\title{
6 Conclusion: "Through the telephone lines a desire, formless and unaware of itself"
}

Considering the scope of Piazza virtuale as well as the extensive press coverage during its broadcasts, it is astonishing that there were hardly any final reports on this ground-breaking artistic television experiment. The press work had ended with the conclusion of the project and no longer stimulated any such final reflections of its own accord; but even the media, which had reported on Piazza virtuale several times, did not publish any final analysis.

All the more important, therefore, are three detailed, subsequent reports: the anonymous article "Auf der Piazza virtuale", which appeared in the weekend supplement of Süddeutsche Zeitung on 14 November 1991 - and thus almost two months after the end of Piazza virtuale - a detailed analysis in the magazine Pablo, ${ }^{1}$ and a long report in the US magazine Wired from 1993. We will look at these texts, before offering some final observations based on our research.

\subsection{A place of first contact}

The article from the Süddeutsche newspaper is remarkable not only because it is practically the only detailed, journalistic reappraisal of Piazza virtuale, but also because it combines a sympathetic point of view with a critical attention to detail. These observations make it clear that the anonymous writer

1 Krajewski, Peter, "Im Chaos aber blüht der Ceist", pablo, no date. This text was found in the collection of articles compiled by the ZDF press office after the end of the project, that is available on the website of our project: http://vangoghtv.hs-mainz.de/wp-content/uploads/2021/02/Presse_Van-Gogh.pdf 
has watched Piazza virtuale regularly. Unlike most other writers, his text is characterised by an understanding of the utopian component of the project, which at the same time does not blind him to the shortcomings of the show. $\mathrm{He}$ is explicitly concerned with compensating for the lack of discursive attention to the project: "Television critics hardly noticed Piazza virtuale, if only because this programme was only shown on 3sat for an hour and a half at noon and on the Berlin cable channelFAB at night", the text begins. "To the few critics who took a brief look, it seemed so chaotic that they mostly dismissed it as a 'trivial, unimportant experiment'."'

This is not to say that he was not as disappointed with the level of conversation at Piazza virtuale as many other commentators. However, the text is informed by an understanding that trying to start a mass conversation on television had an important influence on those interactions. The author not only repeatedly highlights the role of the BBS users, but also states:

An inkling of universal togetherness, of "All men become brothers", vagabonded through the virtual space. Sometimes you even got an idea of what interactive television could become if you reserved a cable channel for it within a city area, for example: a bulletin board for party and demo dates, a place of first contact, which can lead to actual, physical contact. ${ }^{3}$

For the shows on 3sat, however, his judgement is much more critical:

It was as if the people on the phones put out feelers to others, but shied away from making serious contact as they would from an embarrassing touch. They want to show themselves, but still remain anonymous: So they stuck to first names and hacker pseudonyms, to "How are you?" and "Where are you from?", to any number of questions that sooner or later led to the dead end of "Doesn't anyone have anything to say?" Through the telephone lines a desire for the Piazza virtuale forced its way in, apparently still formless, unaware of itself. Most callers did not know what to say, but they wanted to be there, to be part of it. Something was going to happen - only what? ? $^{4}$

\footnotetext{
2 "Auf der 'Piazza Virtuale', Süddeutsche Zeitung, 14/15 November 1992.

3 lbid.

4 lbid.
} 
The author also criticises the attempts of the creators of the show to lead the discussions and set priorities:

But the Kassel media artists ... did not trust the spirits they had called up ... In any case, some of the Piazza virtuale coordinators, especially Salvatore Vanasco, slipped into the role of animators. They gave topics for the callers to talk about - whether they wanted to or not. Sometimes they were asked to tell how they felt when they danced, other times what they thought about violence against foreigners. But the callers only played along half-heartedly and reluctantly, and hardly anything came out except diffuse chit-chat about their feelings. ${ }^{5}$

The posthumous analysis of Piazza virtuale accurately summarises the conceptual problems of the project, without denying that it was part of an emerging media development:

The 100 days of Piazza virtuale at least proved that there is a strong demand for interactive television. The other lesson to be learned from this experiment is that this demand cannot be satisfied with the offerings of the Kassel troupe. From the bird's-eye view of long-term technology policy, Piazza virtuale is likely to prove that the idea of television as an open event for everyone is a dead end: Television as an offering for many and television as an offering by many seem to exclude each other. At any rate, the Kassel artists have spared the corporations from having to explore this dead end by themselves. ${ }^{6}$

The essay in the design magazine Pablo also emphasises the possibilities of free interaction that were inherent in the format, but at the same time points out that Van Gogh TV did not stick to this concept:

During live shows, moderators occasionally appeared (but only acoustically) who gave the participants specific instructions or acted as interpreters in the dialogue with foreign participants. Sometimes questions were put into the mouth of a participant when he couldn't think of anything clever to say. The question inevitably arises as to whether this did not deprive the voiceless

5 Ibid.

6 lbid. 
person of the chance to find something to say. These ad hoc changes simply resulted from the dilemma that 100 days to test a new form of communication very soon proved to be too short.?

The same author, however, also had a good eye for the moments when the audience empowered itself despite the given format and the attempts to control the discourse: "A participant with the pseudonym 'Booty', for example, appeared more and more frequently over time on the computer chat, sometimes participating in the drawing programme, asking afterwards in the Coffeehouse how his work had been liked, and generally moving very self-confidently through the show. An example that at least individual viewers had emancipated themselves into participants."

The reportage that appeared six months later in the newly founded American magazine Wired is a blueprint for the kind of hype with which the paper was to report on American IT companies over the next two decades - except that here a European art project became the subject of the kind of prose that soon earned Wired the accusation of serving as the central organ of an unleashed, neoliberal internet ideology. The paper, which had been developed by its founders Louis Rossetto and Jane Metcalfe as a "Rolling Stone for technology", had made it its business to describe the cultural, social and political effects of digitalisation. ${ }^{9}$

The internet, which would eventually bring the most significant changes and redeem many of the hopes for the future triggered by other technologies, was still little known at that time. (On 30 April 1993 - around the time the May issue of Wired with the story about Van Gogh TV hit the news stands - Tim Berners-Lee published his software for the World Wide Web, an important step in bringing the internet to the masses. Apparently, Van Gogh $\mathrm{TV}$ even had an internet connection in its container studio in Kassel during Piazza virtuale, but did not use it for the show.)

7 Krajewski, "Im Chaos aber blüht der Ceist".

$8 \mathrm{lbid}$.

9 Other articles in this issue - in which the Internet is repeatedly referred to as the "Matrix"are about, among other things, Japanese game designer Tsuyoshi Takashiro's game Wacky Races for the unsuccessful 3DO game console, the virtual reality installation The Cave, the robot performance group Survival Research Laboratories, and emoticons, the "combinations of letters sometimes found at the end of email messages that are the online counterpart of body language". 
Because the internet was still little known at that time, the work of Van Gogh TV seemed to confirm many of the prophecies and predictions of the future that were being discussed at the time about digital and interactive media. With Piazza virtuale they had, according to Wired, "driven a stake through the sclerotic heart of that 50-year-old bloodsucker, television"; the group had aimed at "new collaborative art forms, new political and social forms of organisation and the creation of a true 'communicatopia". ${ }^{10}$

\subsection{Voices from the internet}

It is interesting to see how the few voices "from the internet" that made direct reference to Piazza virtuale assessed the project. On 22 June 1992, at 1.13 p.m., Lothar Fritsch, a computer science student at Saarland University, posted a detailed text about Piazza virtuale in the newsgroup de.soc.kultur. These newsgroups were, at that time, the fora for debate on the internet - a forerunner of the social media of the present.

After long descriptions of various broadcast segments, he comes to this conclusion: "Anyone who has access to the internet can safely forget about Piazza virtuale. For someone who uses IRC, plays MUD, gets a few megabytes of software via FTP between work and dinner while reading the news or does everything via X-Win at the same time, Piazza is a bitter disappointment."11 Fritsch proves himself to be an internet expert by mentioning in detail just about all the internet protocols that were available to a small cast of computer specialists before the introduction of the World Wide Web. For him, Piazza virtuale obviously could not replace the forms of communication he had got to know on the internet.

Even in an online discussion that unfolded between 2 and 18 July in the newsgroup de.comm.misc, the assessment of Piazza virtuale is rather reserved. Bernd Raschke, for example, emphasises: "As a computer science student, you have certainly already got used to dealing with email, ftp, irc, etc., but many people have not had such experiences. I think this virtual pizza :-) is a successful gag."12 Manuel Friedrich has this to say:

\footnotetext{
10 Marshall, "The Medium is the Mission".

11 en.soc.kultur, 22 June 1992.

12 de.comm.misc, 6 June 1992.
} 
In my opinion, VCTV is already part of the culture - the communication culture. Everything that happens on the internet, in the mailboxes or even on BTX is unknown to the majority of the population. When someone comes along and puts it on the TV screen in such a concentrated way and even gives everyone the opportunity to take part, then the whole thing has something culture-shaping about it. After all, we are dealing here with new forms of communication that are being tested. The fact that only crap comes out of it is more the fault of the users than of the providers. ${ }^{13}$

\subsection{Was Piazza virtuale a social medium?}

Was it really the fault of the users that only crap came out of Piazza virtuale? Or were Van Gogh TV's design decisions and the structure of the show to blame? Technical choices in the design of platforms are never neutral, but influence the kind of interaction they make possible.

Realised utopias are probably always a disappointment; especially when - as in the case of Piazza virtuale - they are so quickly overtaken by reality. A hypothesis that stood at the beginning of the research on Piazza virtuale was that the format was an early form of a social medium. By returning to this initial question and comparing the kind of interaction that was possible at Piazza virtuale with that which takes place today on the internet, I want to provide a concluding assessment of the project.

It would be too easy to make the point that Piazza virtuale was a failed attempt to organise the kind of individual and distributed communication that is typical of the internet as a mass medium. This had already been noticed by attentive observers in 1992. In the magazine Ohne Titel an anonymous author wrote:

It seems as if television is to be forcibly turned into something that contradicts its actual structure. The result is a version of the television, for which there is actually no need ... Despite all the criticism, however, the positive aspect of Van Gogh TV must not be overlooked: The Piazza virtuale ... makes the one-dimensionality of its communication obvious. It explores the possibilities of television and reaches its limits. The intention of the makers of Van

13 de.comm.misc, 7 June 1992. 
Gogh TV to break up the viewer's isolation, his passive attitude, his renunciation of real social contacts and to instead open up possibilities of intervention, self-determination and two-way communication is therefore fully justified. ${ }^{14}$

After a quarter of a century of internet, we know that television was not the appropriate medium for this type of communication. Nevertheless, Piazza virtuale enabled some of the activities that are the bread and butter of contemporary internet culture. These characteristics of internet culture include the creation or exchange of information, ideas, professional interests and other types of self-expression, as noted in a recent article that reviewed the relevant literature and identified common characteristics of current social media services. Another trait of social media is the production of user-generated content and the fact that it enables the development of social networks through which users connect with other individuals and groups. ${ }^{15}$

All of this is also true of Piazza virtuale: in various ways, users could get involved in the show and thus exchange information and communicate with each other. This occasionally also led to contacts that went beyond the medium or even to the creation of virtual communities like that of the Piazza virtuale fans who called in regularly and who even travelled together to Kassel to be present during production of the show.

But contacts were also made among the callers and by fax that went beyond the broadcast. As a report to Telekom notes, the insertion of a fax with a telephone number led to a good number of calls: "According to our tests, for example, a broadcast fax number leads to between 10 and 50 responses." This feature did not play a major role for the show because it was live. While today's social media have archived the contact information for their users in a database, at Piazza virtuale telephone numbers were not recorded. Interestingly, viewers of Piazza virtuale were already looking for a way around for this problem: time and again, callers to Coffeehouse asked users of mailbox

\footnotetext{
14 "Van Cogh TV", Untitled IX Journal for Enigmatic Art Appreciation, no date.

15 Obar, Jonathan A.; Wildman, Steve, "Social Media Definition and the Governance Challenge: An Introduction to the Special Issue", Telecommunications Policy 39 (9), pp. 745-750. The paper identifies two other characteristics that obviously do not apply to Piazza virtuale: that social media are Web 2.0 internet-based applications, and that users create service-specific profiles.

16 Interim report, Telecom.
} 
to write their telephone number in the chat so that it would be visible on the screen for a longer period of time.

However, in Piazza virtuale it was structurally impossible to implement this kind of audience feedback. The "self-generating" character of the show did not go so far as to allow the audience to influence the structure; they had to accept what was offered. This also sets the show apart from offerings on the internet, which at the time was being developed by its users to suit their needs and interests. This kind of swarm intelligence, which really made the internet an autopoetic system, could not be harnessed by Piazza virtuale. Van Gogh TV had proclaimed that its work was the channel it created and that the content came from the audience - but in order to be really successful, the audience would have had to be able to influence the channel itself.

So, paradoxically, Piazza virtuale was simultaneously too open and too closed. Four callers randomly thrown together do not necessarily have common interests that could lead to a meaningful conversation. At the same time, the level of conversation on Piazza virtuale always did rise when there was common ground among the callers, as with the aforementioned tech-savvy satellite audience that watched the show during the Olympus broadcasts. With segments that had a thematic brief, such as Marketplace, the level of engagement and intensity of communication increased. At that time, the internet had already developed methods to bring together interest groups, for example the newsgroups, later web forums or user groups in social media.

In the Introduction, I pointed to the empowerment and DIY ethic of punk, the inclusion of the audience in performance art and the artistic critique of the traditional workplace as the roots of Van Gogh TV's work, which led to a "new spirit of capitalism". The ability of the audience to move "from consumer to producer" (Brecht) was indeed the aim of Piazza virtuale. But this was nevertheless subject to great restrictions in the actual show.

The limits and problems of audience involvement in the performance art of Ponton predecessor Minus Delta t were taken to a logical conclusion by Piazza virtuale. Already with Minus Delta $t$, the possibilities for audience participation were limited to reacting to the group's provocations. The artistic goal of Minus Delta t might have been to "create situations" that would turn the spectator into a participant, as called for by Guy Debord. However, the practice was often so confrontational that it left the audience with little choice with regard to their reactions. A similar pattern emerged at Piazza virtuale. Here, however, the audience often chose not to engage in the intended 
fashion with the possibilities to interact offered by the show. Piazza virtuale was not as "self-generating" or "autopoetic" as its creators had wanted it to be. Eventually, the internet gave its users more flexible structures for interaction and self-expression.

Today, the business models of many internet companies are built on just this kind of interaction and self-expression - which brings us to the last point: Piazza virtuale was not organised by a company, but by an artists' group and public broadcaster that were not profit-oriented, but committed to a common good. It was the last time a public broadcaster in Germany was involved in building an infrastructure for a communications network beyond radio and television. Afterwards, this field of operation was left completely to the forces of the free market, and the consequences are well known: Social media companies such as Facebook, YouTube or Telegram, whose business model is based on polarisation, radicalisation and lack of responsibility, play an important role in the spread of fake news, conspiracy theories and crackpot propaganda.

That the emergence of a new form of publicity should not be left to profit-driven companies, as happened later with social media, is perhaps the most important legacy of Piazza virtuale. The management of 3 sat appointed a broadcasting manager who ensured that the anonymous audience could not blast any insult, obscenity or radical political message into the ether. In the case of social media, it would take over a decade before these companies began to take some kind of control over their channels. To this day, they fulfil their obligations in this regard only carelessly and haphazardly.

At Piazza virtuale, on the other hand, from the very beginning a 3 sat staffer made sure that rules of law and common decency were not violated. She was called a "censor" by the group, but actually took on a task that today is called "content moderation".

Those who set up new communication channels also have a responsibility for their development, content and social consequences - that is possibly the most important lesson that can be learned from Piazza virtuale today. 


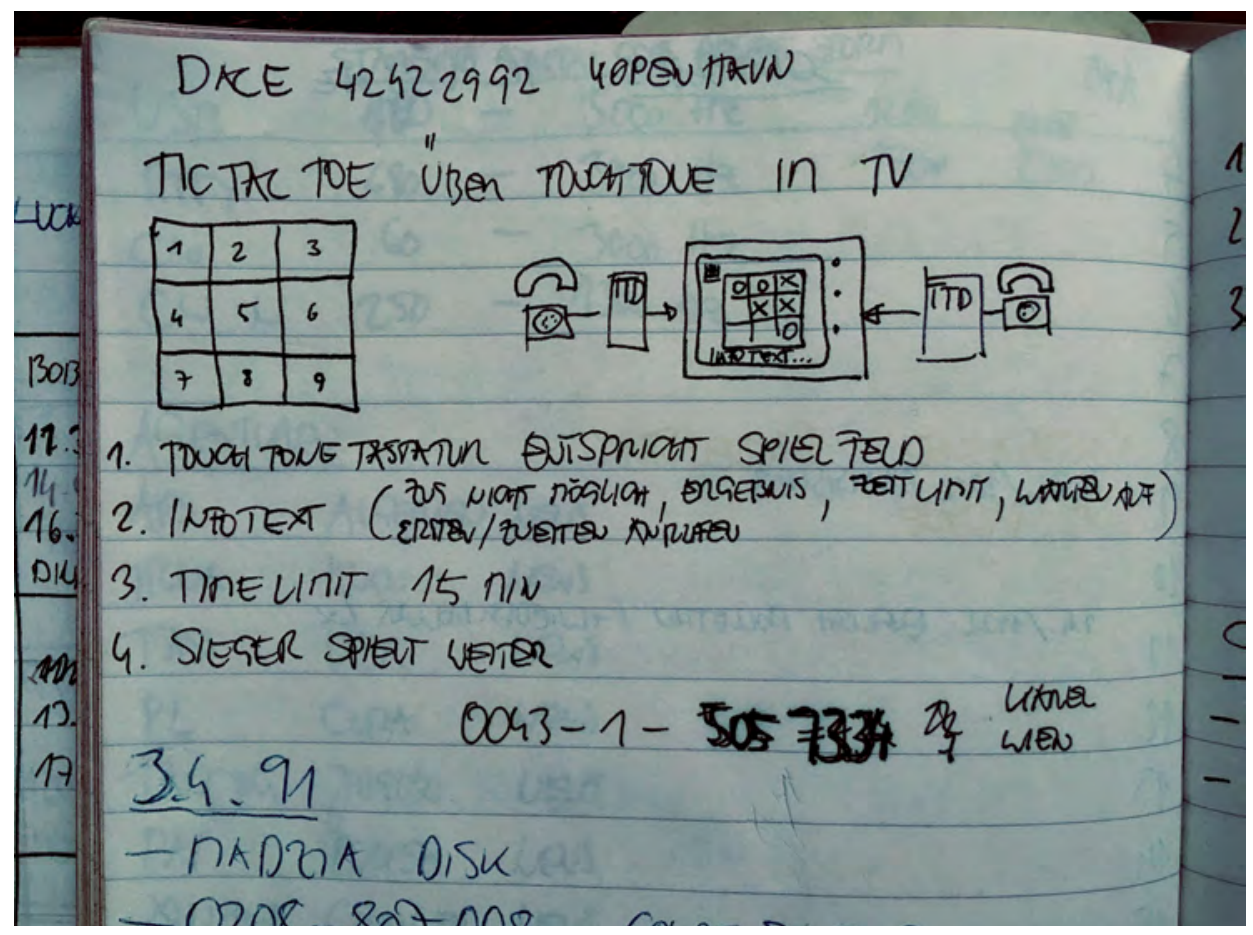

The idea to control television content via touch tone telephone was mentioned for the first time in the sketchbook of Benjamin Heidersberger in April 1991 